\title{
Influência do uso de anticoncepcionais hormonais orais sobre o número de células de Langerhans em mulheres com captura híbrida negativa para papilomavirus humano
}

\author{
Langerhans' cells: influence of the of oral contraceptives by women with negative hybrid capture \\ for human papillomavirus
}

\author{
Nelson Shozo Uchimura ${ }^{1}$, Julisa Chamorro Lascasas Ribalta ${ }^{2}$, José Focchi ${ }^{3}$,
} Edmund Chada Baracat ${ }^{4}$, Taqueco Teruya Uchimura ${ }^{5}$

\section{RESUMO}

Objetivo: estudar a influência do uso de anticoncepcionais orais (AO) sobre o número de células de Langerhans em mulheres sem infecção cervical por papilomavírus humano (HPV). Métodos: foram incluídas trinta mulheres com alterações citológicas e biópsia dirigida pela colposcopia com amostras de colo uterino sem sinais de infecção por HPV. A ausência de DNA de HPV foi confirmada pela captura híbrida. As células de Langerhans foram identificadas pela reação de imunohistoquímica com uso de antígenos anti-S100. As células visualizadas em microscopia de luz foram contadas utilizando o software Cytoviewer. Para análise estatística utilizou-se o teste não paramétrico de soma das ordens de Wilcoxon. Resultados: a média do número de células de Langerhans em mulheres usuárias de AO foi de 320,7/.mm² e em não usuárias 190,7/mm², não sendo esta diferença significante. Na camada intermediária do epitélio cervical observou-se tendência ao aumento dessas células, com as médias $192,1 / \mathrm{mm}^{2}$ para usuárias e $93,4 / \mathrm{mm}^{2}$ para não usuárias de $\mathrm{AO}(\mathrm{p}=0,05)$. Conclusões: no presente estudo não se observou diferença significativa no total de células de Langerhans entre as usuárias e não usuárias de AO, porém, na camada intermediária do epitélio observou-se tendência ao aumento no número dessas células entre as usuárias de AO. Este resultado sugere que os AO podem induzir alterações no número das células de Langerhans, considerando porém o limitado número de casos, este achado não pode ser confirmado.

PALAVRAS-CHAVE: Células de Langerhans; Anticoncepcionais orais; Hormônios; Imunohistoquímica; Infecções por Papillomavirus

\section{ABSTRACT}

Purpose: to study the influence of the use of oral contraceptives (OC) on the number of Langerhans' cells in women without cervical infection by human papillomavirus (HPV). Methods: thirty women who presented abnormal cervical cytology and colposcopy-guided biopsy with samples of uterine cervix negative for HPV were selected. The absence of HPV DNA was confirmed by hybrid capture. Langerhans' cells were identified by immunohistochemistry using anti-S100 antigens. The cells visualized in light microscopy were counted using the Cytoviewer software. The nonparametric Wilcoxon rank sum test was employed for statistical analysis. Results: the average number of Langerhans' cells in OC users was $320.7 / \mathrm{mm}^{2}$ and in non-users $190.7 / \mathrm{mm}^{2}$, this difference being statistically nonsignificant. In the intermediary layer of the cervical epithelium a tendency towards the increase of these cells was observed, with the averages $192.1 / \mathrm{mm}^{2}$ for OC users and $93.4 / \mathrm{mm}^{2}$ for non-users $(\mathrm{p}=0.05)$. Conclusions: the present study reports a tendency towards the increase in the number of the Langerhans' cells among OC users. This result suggests the OC may induce alterations in the number of Langerhans' cells, but considering the limited number of cases, more studies should be developed for a definitive conclusion.

KEYWORDS: Langerhans cells; Contraceptives, oral; Hormones; Immunohistochemical; Papillomavirus infections

Projeto desenvolvido na Universidade Federal de São Paulo - UNIFESP - Hospital São Paulo e financiado pela Fundação Araucária - Programa de Apoio ao Desenvolvimento Científico e Tecnológico do Paraná - Curitiba (PR) - Brasil.

1 Professor Adjunto do Departamento de Medicina, Chefe da Divisão de Ginecologia e Obstetrícia do Hospital Universitário de Maringá, Universidade Estadual de Maringá - UEM - Maringá (PR) - Brasil.

2 Professora Adjunta do Departamento de Ginecologia, Coordenadora do Núcleo de Prevenção de Doenças Ginecológicas da Universidade Federal de São Paulo - UNIFESP - São Paulo (SP) - Brasil.

3 Professor Adjunto do Departamento de Ginecologia, Núcleo de Prevenção de Doenças Ginecológicas, Universidade Federal de São Paulo - UNIFESP - São Paulo (SP) - Brasil.

4 Professor Titular do Departamento de Ginecologia, Coordenador da Pós-Graduação em Ginecologia da Universidade Federal de São Paulo - UNIFESP - São Paulo (SP) - Brasil.

5 Professora Adjunta do Curso de Pós-graduação em Enfermagem, Disciplina de Epidemiologia e Estatística da Universidade Estadual de Maringá - UEM - Maringá (PR) - Brasil.

Correspondência: Nelson Shozo Uchimura

Rua Arthur Thomas, 23 apto 901 -87013-250 - Maringá - Paraná - Telefone/Fax: (44) 3226-6363 - e-mail: nuchimura@brturbo.com.br

Recebido em: 29/10/2004

Aceito com modificações em: 27/12/2005

Rev Bras Ginecol Obstet. 2005; 27(12): 726-30 


\section{Introdução}

As células de Langerhans (CLs) são componentes importantes no sistema de imunovigilância celular contra infecções virais e tumorais e têm a função de apresentar os antígenos virais ou tumorais ativando especificamente os linfócitos. O mecanismo dessa apresentação antigênica começa a partir da captura do antígeno pelas CLs, sendo então associado às moléculas do complexo de histocompatibilidade principal (MHC) e, a seguir, exposto ao linfócito $\mathrm{T}$ específico ${ }^{1}$. Comprovando a importância dessa resposta imunológica, verificouse em pacientes com carcinoma cervical a presença das CLs juntamente com linfócitos CD4, células natural killer e linfócitos $\mathrm{B}^{2}$.

Essas células estão localizadas principalmente nas camadas basais e intermediárias do epitélio escamoso. Na camada basal, apresentam citoplasma abundante e raros dendritos, junto das células escamosas basais, ao passo que na camada intermediária, o citoplasma é escasso e distribuem seus processos dendríticos aos vasos do estroma subepitelial. Esse fato sugere tanto a migração dessas células quanto a transferência de informações antigênicas para as células endoteliais dos vasos ${ }^{3}$.

Diversos tipos de papilomavirus humano (HPV) estão associados ao câncer de colo uterino, porém o HPV16 e o 18 são os tipos mais comumente associados a lesões malignas do colo. Essa infecção é geralmente crônica mesmo na adolescência quando o sistema imunológico está francamente ativo. A cronicidade dessa infecção em hospedeiro imunocompetente sugere falha na apresentação do antígeno viral ao sistema imunológico ou no reconhecimento das células infectadas pelo HPV pela reação específica induzida ${ }^{4}$. No epitélio escamoso do trato genital feminino as CLs são responsáveis pelo reconhecimento, processamento e apresentação ao sistema imunológico. Connor et al. ${ }^{5}$ encontraram redução significativa de CLs S100 positivas tanto na infecção por HPV como em neoplasias intra-epiteliais cervicais sugerindo que a infecção por HPV de algum modo inibe a migração ou maturação dessas células.

A alta taxa de regressão espontânea da infecção por HPV e a evolução somente de alguns casos para malignização sugerem que a infecção viral por si só não desencadeia a malignização e que outras variáveis estão envolvidas neste processo, tais como a irradiação, fumo e hormônios ${ }^{6}$.

Entre os fatores hormonais, destaca-se o uso de contraceptivos hormonais, pela sua repercussão social e econômica, acrescidos ao risco de de- senvolvimento de neoplasia intra-epitelial cervical e câncer invasor do colo uterino. Atualmente, milhões de mulheres no mundo usam os contraceptivos hoemonais, incluindo os anticoncepcionais orais e progestágenos de longa ação, como acetato de medroxiprogesterona injetável e implantes subdérmicos de levonorgestrel ${ }^{6,7}$. Os anticoncepcionais orais, tanto combinados trifásicos quanto os de baixa dose, estão associados ao aumento da transcrição do $\mathrm{HPV}^{8}$. O uso de anticoncepcionais hormonais por mais de cinco anos eleva o risco de desenvolver lesão intra-epitelial de alto grau em pacientes com HPV ${ }^{9}$.

$\mathrm{O}$ anticoncepcional hormonal pode ser importante fator na etiopatogenia do câncer do colo uterino se o uso ocorrer antes do completo desenvolvimento do trato genital feminino, isto é, antes dos $17 \operatorname{anos}^{10}$. Do mesmo modo demonstrou-se que o risco para desenvolver adenocarcinoma in situ do colo uterino está aumentado também para as mulheres com longo tempo de uso de anticoncepcionais orais (mais que 12 anos) ${ }^{11}$.

Assim, a influência dos hormônios sobre imunidade tem sido referida pela observação da alta prevalência de HPV na gestação e o efeito de imunodepressão no estado gravídico pela depressão da densidade das $\mathrm{CLs}^{12}$. Alguns fatores biocomportamentais como a menarca após 13 anos e a precocidade sexual antes dos 17 anos também estão associados com a diminuição do número de $\mathrm{CLs}^{13}$.

Diante do exposto, o presente ensaio teve por objetivo estudar a influência do uso de anticoncepcionais orais sobre o número de CLs em mulheres sem a infecção cervical por HPV.

\section{Métodos}

A população foi constituída por 30 mulheres usuárias ou não de anticoncepcionais orais, atendidas no ambulatório da Clínica da Mulher da Secretaria de Saúde do Município de Maringá, PR que apresentavam amostras de colo uterino negativas para HPV, confirmado pela captura híbrida (Digene Diagnostics Inc.). Esta população caracterizou-se pela baixa escolaridade com $63,3 \%$ (19) de analfabetas ou com primeiro grau incompleto, $26,7 \%$ (8) com nível secundário e 10,0\% (3) com nivel superior incompleto. Com relação ao estado civil, 83,3\% (25) eram casadas, $13,3 \%$ (4) solteiras e 3,4\% (1) separadas. A faixa etária variou de 18 a 46 anos, porém $80 \%$ (22) das mulheres tinham de 20 a 39 anos, com a média de 30 anos.

No estudo com abordagem transversal, aleatorizado, foram incluidas as mulheres que 
referiam usar anticoncepcionais orais por mais de três meses e como controle as que não usavam anticoncepcionais orais por periodo também superior a três meses.

Foram excluídas as gestantes, as lactantes e as menopausadas, as usuárias de imunossupressores e de imunoestimuladores nos últimos três meses, bem como as usuárias de drogas e de narcóticos e as portadoras de doenças auto-imunes, neoplasias e diabete.

Anamnese e exame ginecológico completo foram realizados no atendimento inicial, com o preenchimento da ficha clínica específica e agendamento de retorno para a primeira fase do ciclo menstrual para que fosse realizada a biópsia dirigida pela colposcopia. A técnica colposcópica foi feita segundo a rotina do serviço, com embrocação em seqüência de soro fisiológico, ácido acético $2 \%$ e solução de Schiller $2 \%$.

A amostra da biópsia, retirada da área colposcópica normal, foi dividida em dois fragmentos, sendo um encaminhado para os exames histopatológico e imuno-histoquímico e outro encaminhado para a captura híbrida.

Para o exame da captura híbrida o fragmento foi imerso num tubo de coleta especial contendo $1 \mathrm{~mL}$ de azida sódica $0,05 \%$, sendo depois congelado a $-20^{\circ} \mathrm{C}$ e encaminhado ao laboratório. A técnica utilizada foi a hibridização molecular, por captura de híbridos em microplaca, que utiliza sondas não radioativas, com amplificação da detecção dos híbridos por quimioluminescência. Essa técnica permite diagnosticar os 18 tipos mais comuns de HPV do trato genital e classificar o HPV em dois grandes grupos, o do tipo A, de baixo risco $(6,11,42,43,44)$, e do tipo $B$, de alto risco $(16,18,31,33,35,39,45,51,52,56,58,59,68)$. A sensibilidade do teste para o HPV é igual ou maior que $1,0 \mathrm{pg} / \mathrm{mL}^{14}$.

Os fragmentos cervicais obtidos para exames histopatológico e imuno-histoquímico foram fixados em formalina a $10 \%$ e encaminhados para processamento. A técnica de histopatologia utilizada foi a padronizada no serviço com impregnação em parafina. O bloco de material parafinado foi cortado em micrótomo rotativo manual em espessura de 4 a 5 micra, colocado em lâmina e corado com hematoxilina de Harris e eosina. A lâmina assim preparada foi analisada em microscópio de luz.

Para o método imuno-histoquímico o bloco parafinado de cada amostra teve em média cinco cortes histológicos de 3 a 4 micra distribuídos em lâminas silanizadas e incubadas com anticorpo preparado em coelho, anti-proteína S-100 (DAKO), em solução $1 / 5000$, diluído em solução de albumina a $1 \%$ e azida sódica $\left(\mathrm{NaN}_{3}\right)$ a $0,1 \%$ em solução tamponada com fosfato (PBS). A seguir, foram incubadas com anticorpo de cabra anti-coelho, biotinilado (Vector Laboratories) e aplicado ao complexo estreptavidina-biotina-peroxidase. A reação foi revelada com substrato cromogênico por 3 a 5 minutos, preparado com diaminobenzidina (Sigma, USA) a 0,6\%, peróxido de hidrogênio a $0,06 \%$ e dimetilsulfóxido a $1 \%$ em PBS. Os cortes assim preparados foram contracorados com hematoxilina de Harris e montados em Entellan (Merck) com laminulas.

No método histométrico cada lâmina preparada de imuno-histoquímica foi avaliada em microscópio de luz com aumento de 400 vezes adaptado à microcâmera, sendo sua imagem digitalizada pelo software Cytoviewer. O cálculo da área em micrômetros quadrados por campo foi feito previamente, utilizando a câmara graduada de Neubauer. Conhecida a área examinada por campo contou-se o número das CLs por meio da contagem de núcleos dessas células e de seus perfis citoplasmáticos por milímetro quadrado.

As CLs S100 positivas foram identificadas pela coloração marrom de seus citoplasmas que se apresentavam, conforme o eixo do corte histológico, em perfis citoplasmáticos de diversas formas, como de ponto, vírgula, filiformes ou mesmo arboriforme. As características qualitativas dos elementos celulares foram estudadas e também melhor visualizadas no monitor de computador.

Quantificaram-se as CLs segundo sua localização nas camadas do epitélio ou do estroma, conforme a divisão histológica do epitélio escamoso em camadas superficial, intermediária e basal.

Para análise estatística dividiu-se a amostra em dois grupos: usuárias $(n=6)$ e não usuárias $(n=24)$ de anticoncepcionais hormonais orais. Calcularam-se a média aritmética e os respectivos desvios padrão do número das CLs por milimetro quadrado. Utilizou-se o teste não-paramétrico de soma das ordens de Wilcoxon (rank sum test). Para todos os testes estatísticos considerou-se o nível de significância de $5 \%(\mathrm{p}<0,05)$.

O presente estudo foi aprovado pela Comissão de Ética Médica do Hospital São Paulo - Universidade Federal de São Paulo.

\section{Resultados}

Todos os fragmentos cervicais, no total de trinta, avaliados pela captura híbrida para HPV, mostraram-se negativos. A média no número de CLs de todas as camadas em mulheres usuárias de anticoncepcionais orais foi 320,7 células $/ \mathrm{mm}^{2}$ e em não usuárias, de 190,7 células $/ \mathrm{mm}^{2}$. Esta diferen- 
ça não foi estatisticamente significante $(p=0,98)$.

$\mathrm{Na}$ análise por camadas histológicas (superficial, intermediária e basal) observou-se que as médias do número das CLs estão sempre elevadas em usuárias de anticoncepcionais orais. Principalmente, na camada intermediária observouse tendência ao aumento das CLs, com as médias de 192,1 células $/ \mathrm{mm}^{2}$ para usuárias e 93,4 células $/ \mathrm{mm}^{2}$ para não usuárias $(\mathrm{p}=0,06)$ (Tabela 1$)$.

Tabela 1 - Número de células de Langerhans por $\mathrm{mm}^{2}$ (densidade) nas camadas superficial, intermediária e basal do epitélio do colo. Distribuição de acordo com uso de anticoncepcionais orais (médias e desvios padrão).

\begin{tabular}{lrrrrr}
\hline Epitélio & \multicolumn{4}{c}{ Anticoncepcionais orais } & $\mathbf{p}^{*}$ \\
Camadas histológicas & Não $(\mathbf{n}=\mathbf{2 4})$ & \multicolumn{2}{c}{$\operatorname{Sim}(\mathbf{n}=\mathbf{6})$} & \\
& média & DP & \multicolumn{1}{c}{ média } & \multicolumn{1}{c}{ DP } & \\
\hline Superficial & 4,1 & 6,4 & 20,4 & 31,1 & 0,09 \\
Intermediária & 93,4 & 67,3 & 192,1 & 149,8 & 0,05 \\
Basal & 24,0 & 23,6 & 48,3 & 48,1 & 0,98 \\
Todas as camadas & 190,7 & 134,0 & 320,7 & 205,6 & 0,98 \\
\hline
\end{tabular}

*Teste de Wilcoxon (rank sum test).

\section{Discussão}

Os hormônios sexuais, incluindo os contraceptivos hormonais, influenciam a suscetibilidade e a predisposição às infecções do trato genital inferior. Seus efeitos são variados e dependem do patógeno e dos hormônios envolvidos. Assim, os contraceptivos orais podem aumentar o risco de infecção genital por clamídea e monília e para doença inflamatória pélvica, e a vaginose bacteriana atuaria como fator de proteção ${ }^{15}$.

Os estrógenos exercem importante papel na resposta imunológica na produção de anticorpos; assim, há aumento da expressão de IgA e IgG no muco cervical durante o pico ovulatório de estrógeno no ciclo menstrual. Em usuárias de anticoncepcionais hormonais a quantidade de IgA detectada no muco cervical é três vezes maior do que no pico ovulatório $^{16}$. Por outro lado, o ciclo menstrual parece não influenciar a imunidade mediada por células, pois estudo com biópsias seriadas do epitélio vaginal em 74 mulheres não mostrou alterações significativas no número das CLs, macrófagos, linfócitos CD4 e CD8 e em neutrófilos ${ }^{17}$.

O efeito dos contraceptivos hormonais sobre o sistema imunológico depende dos agentes infectantes ou do estágio da infecção. Em infecção primária por HPV há um efeito protetor, porém a persistência da infecção por HPV está associada com a progressão da infecção para o câncer cervical. Assim, adolescentes que usam anticoncepcionais orais têm incidência significativamente mais baixa de infecção por HPV do que as não usuárias ${ }^{18}$.
Esses dados da literatura são contraditórios: em trabalho de revisão não foi encontrada nenhuma associação entre a infecção por HPV e o uso prolongado de anticoncepcionais hormonais ${ }^{19}$.

Por outro lado, outros estudos referem que os anticoncepcionais favorecem a oncogênese, pois interferem diretamente no metabolismo do ácido fólico, bem como na suspensão da função de imunovigilância tumoral ou mesmo pela maior exposição do epitélio glandular (ectopia) aos agentes agressores presentes no ambiente vaginal ${ }^{7}$.

O estudo dos efeitos dos contraceptivos hormonais sobre o número de CLs do epitélio do trato genital feminino tornou-se de fundamental importância, com trabalhos relatando a infecção intraepitelial das CLs pelo vírus de imunodeficiência dos macacos $^{20}$. Diversos trabalhos referem também diminuição do número de CLs nas infecções por HPV e aumento das mesmas em presença de NIC ${ }^{21}$.

Neste estudo, não se observou diferença significativa entre o número de CLs de usuárias e não usuárias de anticoncepcionais orais. Este resultado é semelhante ao observado por outros. Ildgruben et al. ${ }^{22}$ analisaram três grupos de usuárias de contraceptivos hormonais: o grupo de anticoncepcionais orais ( $\mathrm{n}=15)$, o grupo que empregava acetato de medroxiprogesterona trimestral $(n=15)$ e o grupo de levonorgestrel subdérmico $(n=15)$, não encontrando diferença significativa no número de CLs, comparando com o grupo controle de não usuárias.

Os efeitos de progesterona (acetato de medroxiprogesterona) em dose única foram estudados em 20 mulheres com biópsias seriadas por 3 me$\operatorname{ses}^{23}$. Outro estudo avaliou os efeitos do mesmo hormônio em uso prolongado de 2 a 3 anos em 20 usuárias e 20 controles $^{24}$. Em ambos os estudos não se demonstrou alteração siginificativa no número de CLs S-100 positivas. Outros, no entanto, demonstraram que o uso de progesterona em óvulos vaginais durante 10 dias aumenta siginificativamente o número de CLs (CD1a) no epitélio vaginal ${ }^{25}$.

No presente estudo não se observou diferença significante no número total de CLs no epitélio, porém no estudo por camadas histológicas observou-se tendência ao aumento na média dessas células na camada intermediária. Este resultado pode estar associado ao tamanho da amostra, com seis usuárias de anticoncepcionais orais e 24 controles, bem como ao marcador imuno-histoquímico utilizado (S-100). Definitivamente há influência dos anticoncepcionais orais sobre as CLs correlacionando-se dosagens e tipos hormonais bem como o tempo de uso. A compreensão da atuação destes hormônios no sistema imunológico poderá contribuir para o desenvolvimento de vacinas eficazes contra infecções virais e câncer de colo uterino. 


\section{Referências}

1. Roig de Vargas-Linares C. Langerhans cells and Tlymphocytes in the normal human ectocervix defined by monoclonal antibodies and electron microscopy. Microsc Electron Biol Celular. 1989;13(1):53-63.

2. Hachisuga T, Fukuda K, Kawarabayashi T. Local immune response in squamous cell carcinoma of the uterine cervix. Gynecol Obstet Invest. 2001;52(1):3-8.

3. Morelli AE, di Paola G, Fainboim L. Density and distribuition of Langerhans cells in the human uterine cervix. Arch Gynecol Obstet. 1992;252(2):65-71.

4. Tindle RW, Frazer IH. Immune response to human papillomaviruses and the prospects for human papillomavirus-specific immunisation. Curr Top Microbiol Immunol. 1994;186(1):217-53.

5. Connor JP, Ferrer K, Kane JP, Goldberg JM. Evaluation of Langerhans' cells in the cervical epithelium of women with cervical intraepithelial neoplasia. Gynecol Oncol. 1999;75(1):130-5.

6. Hildesheim A, Reeves WC, Brinton LA, Lavery C, Brenes M, De La Guardia ME, et al. Association of oral contraceptive use and human papillomaviruses in invasive cervical cancers. Int $\mathrm{J}$ Cancer. 1990;45(5):860-4.

7. Harper JM, Levine AJ, Rosenthal DL, Wiesmeier E, Hunt IF, Swendseid ME, et al. Erythrocyte folate levels, oral contraceptive use and abnormal cervical cytology. Acta Cytol. 1994;38(3):324-30.

8. Vandenvelde C, Van Beers D. Risk factors inducing the persistence of high-risk genital papillomaviruses in the normal cervix. J Med Virol. 1992;38(3):226-32.

9. Negrini BP, Schiffman MH, Kurman RJ, Barnes W, Lannom L, Malley K, et al. Oral contraceptive use, human papillomavirus infection, and risk of early cytological abnormalities of the cervix. Cancer Res. 1990;50(15):4670-5.

10.Daling JR, Madeleine MM, McKnight B, Carter JJ, Wipf GC, Ashley R, et al. The relationship of human papillomavirus-related cervical tumors to cigarette smoking, oral contraceptive use, and prior herpes simplex virus type 2 infection. Cancer Epidemiol Biomarkers Prev. 1996;5(7):541-8.

11. Madeleine MM, Daling JR, Schwartz SM, Shera K, McKnight B, Carter JJ, et al. Human papillomavirus and long-term oral contraceptive use increase the risk of adenocarcinoma in situ of the cervix. Cancer Epidemiol Biomarkers Prev. 2001;10(3):171-7.

12.Poppe WA, Peeters R, Drijkoningen M, Ide PS, Daenens P, Lauweryns JM, et al. Cervical cotinine and macrophage-Langerhans cells density in the normal human uterine cervix. Gynecol Obstet Invest. 1996;41(4):253-9.
13. Uchimura NS, Ribalta JCL, Focchi J, Baracat EC, Uchimura TT. Fatores biocomportamentais e as alterações no número das células de Langerhans. Rev Bras Ginecol Obstet. 2004;26(4):289-94.

14.Lorincz AT. Molecular methods for the detection of human papillomavirus infection. Obstet Gynecol Clin North Am. 1996;23(3):707-30.

15. Baeten JM, Nyange PM, Richardson BA, Lavreys L, Chohan B, Martin HL Jr, et al. Hormonal contraception and risk of sexually transmitted disease acquisition: results from a prospective study. Am J Obstet Gynecol. 2001;185(2):380-5.

16. Patton DL, Thwin SS, Meier A, Hooton TM, Stapleton AE, Eschenbach DA. Epithelial cell layer thickness and immune cell populations in the normal human vagina at different stages of the menstrual cycle. Am J Obstet Gynecol. 2000;183(4):967-73.

17. Franklin RD, Kutteh WH. Characterization of immunoglobulins and cytokines in human cervical mucus: influence of exogenous an endogenous hormones. J Reprod Immunol. 1999;42(2):93-106.

18. Brabin L. Interactions of the female hormonal environment, susceptibility to viral infections, and disease progression. AIDS Patient Care STDS. 2002;16(5):211-21.

19. Green J, Berrington de Gonzales A, Smith JS, Franceschi S, Appleby P, Plummer M, et al. Human papillomavirus infection and use of oral contraceptives. Br J Cancer. 2003;88(11):1713-20.

20. Hu J, Gardner MB, Miller CJ. Simian immunodeficiency virus rapidly penetrates the cervicovaginal mucosa after intravaginal inoculation and infects intraepithelial dendritic cells. J Virol. 2000;74(13):6087-95.

21. Morelli AE, Sananes C, Di Paola G, Paredes A, Fainboim L. Relationship between types of human papillomavirus and Langerhans' cells in cervical condyloma and intraepithelial neoplasia. Am J Clin Pathol. 1993;99(2):200-6.

22.Ildgruben AK, Sjöberg IM, Hammarström ML. Influence of hormonal contraceptives on the immune cells and thickness of human vaginal epithelium. Obstet Gynecol. 2003;102(3):571-82.

23.Mauck CK, Callahan MM, Baker J, Arbogast K, Veazey $\mathrm{R}$, Stock R, et al. The effect of one injection of DepoProvera on the human vaginal epithelium and cervical ectopy. Contraception. 1999;60(1):15-24.

24.Bahamondes L, Trevisan M, Andrade L, Marchi NM, Castro S, Diaz J, et al. The effect upon the human vaginal histology of the long-term use of the injectable contraceptive Depo-Provera. Contraception. 2000; 62(1):23-7.

25.Wieser F, Hosmann J, Tschugguel W, Czerwenka K, Sedivy R, Huber JC. Progesterone increases the number of Langerhans cells in human vaginal epithelium. Fertil Steril. 2001;75(6):1234-5. 